\title{
Botulinum toxin A in children with cerebral palsy: evaluation of therapy using the Pediatric Evaluation of Disability Inventory (PEDI)
}

\author{
Volker Mall ${ }^{1}$, Janbernd Kirschner ${ }^{1}$, Michaela Linder ${ }^{1}$, Gudrun Schindler ${ }^{1}$, \\ Steffen Berweck ${ }^{2}$, Sabine Stein ${ }^{1}$,Ulla Michaelis ${ }^{1}$, Peter Bernius ${ }^{3}$, \\ Rudolf Korinthenberg ${ }^{1}$, Florian Heinen ${ }^{2}$ \\ ${ }^{1}$ Department of Neuropediatrics and Muscular Disorders, \\ Children's Hospital, University of Freiburg, Germany \\ ${ }^{2}$ Children's Hospital, University of Munich, Germany \\ ${ }^{3}$ Department of Orthopedics, Munich-Harlaching Hospital, Germany
}

\begin{abstract}
Several controlled studies have shown that in children with cerebral palsy, botulinum toxin A (BTX/A) can decrease muscular hyperactivity associated with spasticity and improve function. Studies have hitherto focused on the dimensions of impairment and functional limitations. In this pilot study with BTX/A in children with cerebral palsy, we used the Pediatric Evaluation of Disability Inventory (PEDI) to evaluate the effect of treatment. PEDI is a reliable and valid instrument that focuses on assessing disability in daily life. Patients with cerebral palsy $(n=17$, median age 5.5 years, age range 2.5 to 16.5 years) were treated with BTX/A for pes equinus $(n=8)$ or adductor spasm $(n=9)$. PEDI assessment was carried out before and 1 month after the first treatment with BTX/A. Scaled scores were calculated according to the user's manual for the Mobility domain with scores near , 0 " reflecting low capability and scores near „100" reflecting high capability. We found a significant improvement in the mobility domain-caregiver dimension from $52.3 \% \pm 26.6 \%$ to $56.6 \% \pm$ $26.7 \%$ (mean, standard deviation $P<0.05$ ), as well as in the self care domain-functional skills
\end{abstract}

Correspondence: Volker Mall, M.D.,

Zentrum für Kinderheilkunde und Jugendmedizin Klinik II: Neuropädiatrie und Muskelerkrankungen, Mathildenstraße 1, 79106 Freiburg, Germany.

Tel: + 4976127043 01, fax: + 497612704344

E-mail: mall@kikli.ukl.uni-freiburg.de

Received: March 14, 2003.

Revised: June 6, 2003.

Accepted: June 19, 2003 from $63.6 \% \pm 18.7 \%$ to $65.2 \% \pm 19.6 \%$ (mean, standard deviation $\mathbf{P}<\mathbf{0 . 0 5})$. Our data indicate that in young patients with cerebral palsy, BTX/ A therapy of the lower extremity can reduce the disability. For these patients PEDI is a valuable assessment instrument that reflects the effect of treatment with BTX/A on the disability. ( $J$ Pediatr Neurol 2003; 1(1): 29-34).

Key words: Botulinum toxin A, cerebral palsy, therapy evaluation, Pediatric Evaluation of Disability Inventory, PEDI.

\section{Introduction}

Intramuscular injection of botulinum toxin A (BTX/A) is a relatively new modality for the treatment of spastic movement disorders in children $(1,2)$. Results of placebo-controlled studies have shown local efficacy and functional benefit for patients with upper extremity spasticity and pes equinus (3-7). Limitations concerning the validity of these studies are due to a relatively low number of patients and the evaluation methods used to assess the functional effect of the treatment. While evaluation of the local effect of BTX/A has been widely established using the Range of Motion (ROM) and Ashworth Scale (8), the evaluation of functional outcome remains a challenge. Ketelaar et al. (9) reviewed 17 instruments that were used in the assessment of functional motor abilities. Of these only two instruments, namely the Gross Motor Function Measure (GMFM) (10) and the Pediatric Evaluation of Disability Inventory (PEDI) (11), were considered as validated and reliable with respect to responsiveness to changes in the patients' clinical condition. The GMFM is based on motor function milestones and evaluates gross motor 
Table 1. Classification of patients according to the type of cerebral palsy and the level of gross motor function impairment (33)

Type of Cerebral Palsy

Spastic diparesis $(\mathrm{n}=9)$

Spastic tetraparesis $(\mathrm{n}=6)$

Spastic hemiparesis $(\mathrm{n}=2)$

Gross Motor Function Classification System (GMFCS)

Level I: Walks without restrictions; limitations in more advanced gross motor skills $(n=4)$

Level II: Walks without devices; limitations walking outdoors and in the community $(n=5)$

Level III: Walks with assistive mobility devices; limitations walking outdoors and in the community $(n=4)$

Level IV: Self mobility with limitations; children are transported or use power mobility outdoors and in the community $(\mathrm{n}=5)$

Level V: Self-mobility is severely limited even with the use of assistive technology $(n=1)$

function under primarily quantitative aspects. PEDI measures function in more concrete daily activity tasks, which are categorised according to the domains of self-care, mobility, and social function. In turn, each of these is evaluated under the aspects of functional performance capacity, caregiver assistance, and environmental modifications (known as "dimensions"). Both GMFM and PEDI have been used increasingly to assess the effect of BTX/A therapy in patients with cerebral palsy $(\mathrm{CP})$ $(7,12-30)$. PEDI has been used to evaluate BTX/A therapy for upper extremities, showing functional benefits after treatment (30). In the present study, PEDI was used to evaluate the BTX/A treatment of the lower extremities in children with CP.

\section{Materials and Methods}

\section{Patients}

Seventeen patients with cerebral palsy (median age 5.5 years, age range 2.5 to 16.5 years) were treated with BTX/A for pes equinus $(n=8)$ or adductor spasm $(\mathrm{n}=9)$ (Table 1$)$. Patients were included in the study when either pes equinus or adductor spasm were identified as dominant focal motor problem and a functional goal for the treatment could be defined. When pes equinus as well as adductor spasm were prominent, adductor spasm was treated in case a functional goal could be defined. Patients with haemostatic disorders or with fixed contractures were excluded. Patients were classified according to the type of cerebral palsy and the level of gross motor function impairment (Table 1). Approval from the local ethics committee (ethical committee University of Freiburg) and informed consent from parents of all patients were obtained.

\section{Treatment}

Patients were given intramuscular injections into the adductor muscles and into the gastrocnemius muscle using $27 \mathrm{G}$ needles. Other injected muscles were the medial hamstrings and the muscle tibialis posterior. One vial of BTX/A $\left(\right.$ Botox $^{\circledR}$, Merz, Frankfurt, Germany; Dysport ${ }^{\circledR}$, Ipsen Pharma, Ettlingen, Germany) was dissolved in $2 \mathrm{ml}$ sodium chloride solution $0.9 \%$. A maximal dose of 12 Units Botox ${ }^{\circledR}$ or 30 Units Dysport ${ }^{\circledR}$ per kg body weight and a maximal total dose of 300 Units Botox ${ }^{\circledR}$ or 1500 Units Dysport ${ }^{\circledR}$ were applied. We injected into the proximal third of the muscle. The injection site was determined by palpation of the muscle belly; electromyography was not used. A maximum of $1 \mathrm{ml}$ was applied per injection site; thus, the number of injection sites depended on the volume to be injected. All patients had physiotherapy twice a week; 16 patients were treated according to neurodevelopmental therapy; two patients were treated according to other treatment protocols, including hippotherapy and occupational therapy.

\section{Local parameters of therapy evaluation}

Patients were assessed according to a standardised protocol, before and 4 to 8 weeks after the treatment with BTX/A. The local effect of BTX/A was assessed using passive ROM and the modified Ashworth Scale (8). Positioning and handling during measurement were standardised and carried out each time by the same examiner.

\section{Pediatric Evaluation of Disability Inventory (PEDI)}

According to the user's manual and in accordance with the organisational structure of a outpatient clinic, the PEDI was performed by interviewing the patient's parents. Interviews were performed in parallel by two independent raters, one experienced physiotherapist, and a medical student in most patients 1 month after the treatment with BTX/A. For organisational reasons in two patients the interview had to be conducted retrospectively four and six months after treatment. While the initial interview reflected the pre-treatment status, the second interview referred to the status one month after BTX/A treatment (when a peak benefit is expected). Differences between the two raters 
Table 2. Results of evaluation using the PEDI (scaled scores) pre- and post-treatment with BTX/A

\begin{tabular}{lllll}
\hline \hline & \multicolumn{2}{c}{ Functional Skills } & \multicolumn{2}{c}{ Caregiver Assistance } \\
& Pre & Post & Pre & Post \\
\hline Mobility & 55.8 & 57.4 & 52.3 & $56.6 *$ \\
Domain & $51.4 / 32.5 / 77.5$ & $9 / 32.4 / 81.1$ & $56.1 / 39.0 / 70.5$ & $56.1 / 39.0 / 75.2$ \\
& $(11.4-94.2)$ & $(11.4-94.2)$ & $(0-100)$ & $(0-100)$ \\
Self & 63.6 & $65.2 *$ & 51.3 & 52.0 \\
Care & $64.6 / 54.0 / 73.6$ & $64.6 / 55.25 / 74.9$ & $54.6 / 47.9 / 65.1$ & $54.6 / 47.9 / 68.1$ \\
& $(29.4-100)$ & $(29.4-100)$ & $(0-100)$ & $(0-100)$ \\
Social & 67.9 & 68.7 & 74.5 & 74.1 \\
Function & $66.2 / 55.2 / 83.2$ & $66.2 / 55.2 / 89.1$ & $75.3 / 50.8 / 100$ & $78.6 / 50.8 / 100$ \\
& $(10.5-100)$ & $(10.5-100)$ & $(11.3-100)$ & $(11.3-100)$ \\
\hline
\end{tabular}

$* \mathrm{P}<0.05$. Indicated are the mean (first line), the median, the $25^{\text {th }}$ and the $75^{\text {th }}$ percentile score (second line) as well as the range (third line).

were cleared and reconciled after the interview. PEDI is divided into three domains-namely selfcare, mobility, and social function; in turn each domain is described in three dimensions-functional skills, caregiver assistance, and modification scale. All three domains in the dimension functional skill and caregiver assistance were tested separately for the effect of the therapy. Reliability and validity testing of the PEDI has been conducted in healthy children up to the age of 7 years, when they reach the maximum score of $100 \%$. However, this ceiling effect is not seen in older children with significant handicap, such as cerebral palsy (31).

\section{Gross Motor Function Measure (GMFM)}

GMFM was performed according to the user's manual by two physiotherapists with extensive experience in the application of this test 4-8 weeks after the treatment with BTX/A. They were involved in the official German translation of the GMFM and trained others in its use. The same examiner performed pre- and post-treatment GMFM. According to the user's manual, a goal area for the GMFM was determined before therapy.

\section{Statistics}

Between the follow-up visits, the Wilcoxon test was used to evaluate the differences in PEDI, GMFM, ROM, and the modified Ashworth Scale.

\section{Results}

\section{Local parameters}

BTX/A led to a significant reduction in muscle tone from $1.9 \pm 0.7$ to $1.6 \pm 1.0$ (mean \pm standard deviation, $\mathrm{P}<0.01$ ) as measured by the modified Ashworth Scale. An increase from 48.5\% $\pm 36.5 \%$ to $56.0 \% \pm 32.7 \%$ (mean, standard deviation, $\mathrm{P}<$ $0.05)$ in the passive ROM $(\mathrm{n}=13)$ was seen after the treatment with BTX/A.

\section{PEDI}

After the treatment with BTX/A, patients showed a significant increase in the mobility domaincaregiver dimension from $52.3 \% \pm 26.6 \%$ to $56.6 \%$ $\pm 26.7 \%$ (mean, standard deviation $\mathrm{P}<0.05$ ), as well as in the self care domain-functional skills from $63.6 \% \pm 18.7 \%$ to $65.2 \% \pm 19.6 \%$ (mean, standard deviation, $\mathrm{P}<0.05$, Table 2, Figure 1). Treatment of adductor spasm and pes equinus with BTX/A led to a reduction in caregiver assistance during transfer situations (Table 3).

\section{GMFM}

Although after treatment with BTX/A the GMFM Goal Score increased from $50 \% \pm 29 \%$ to $53 \% \pm 27 \%$ (mean, standard deviation), this change was not statistically significant when considering the entire group (Table 4, $\mathrm{P}>0.05$ ). However, for seven individual patients the increase accounted for more than $5 \%$, which reflects a probable clinically significant improvement. There was no direct correlation between PEDI and GMFM score in this group of patients $(r=-0.15)$.

\section{Case report}

We report a 12-year-old boy with spastic tetraparesis. His perinatal history was complicated by premature birth (26 post gestational week) and amnion infections syndrome. His MRI scan showed significant periventricular leucomalacia. Focal motor problems were spastic muscular hyperactivity of the adductor and hamstring muscles. He was able to stand with help of his parents. For transfer from the wheel-chair to another chair and from the wheel-chair to the toilet he needed the support of his parents. He received 50 Units Botox ${ }^{\circledR}$ into each hamstring and adductor muscle. The total dose was 200 units $(8.7$ units $/ \mathrm{kg}$ body weight). After injection the ability to stand improved and he was able to perform the transfer 


\section{PEDI}

\section{Functional skills \\ Caregiver assistance}

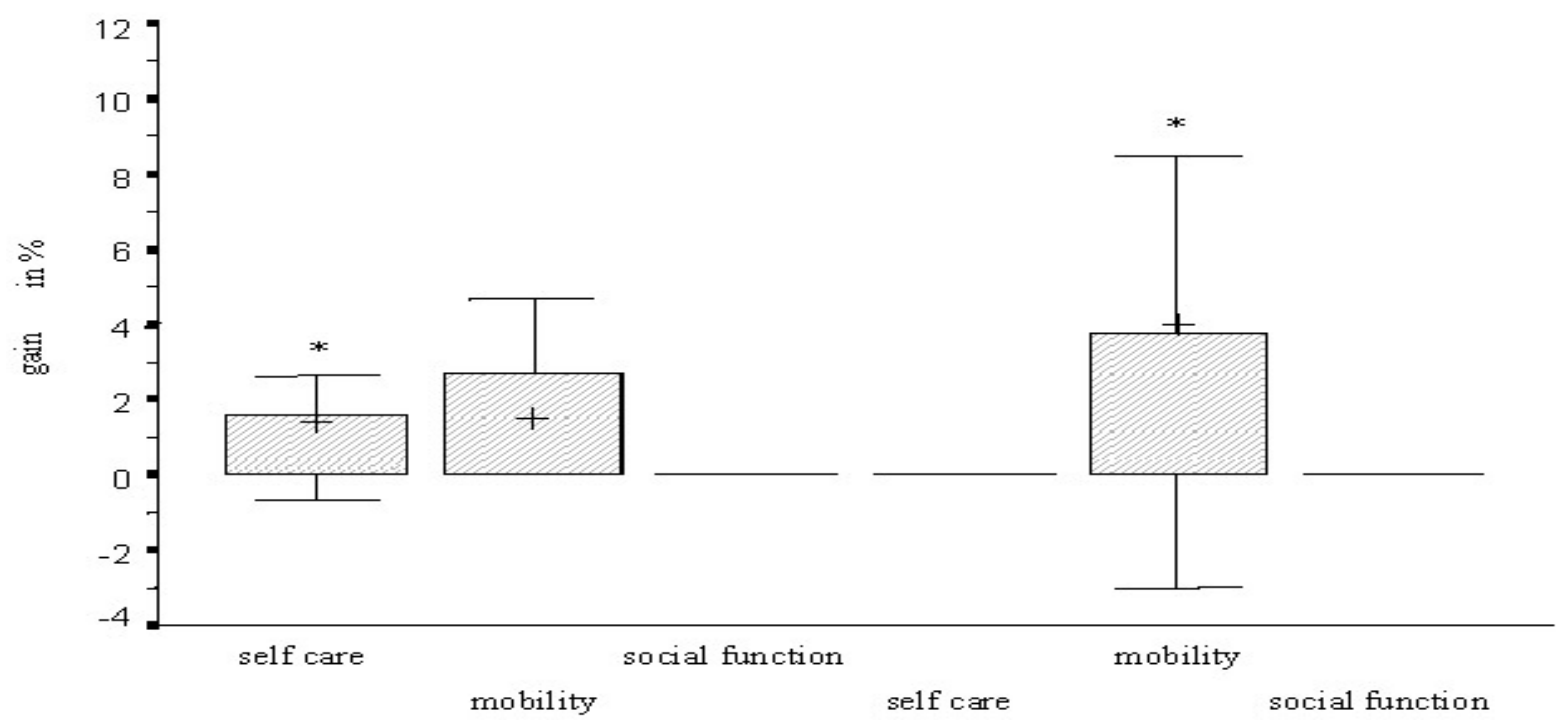

Figure 1. Summary of results obtained by evaluation with PEDI pre- and post BTX/A therapy. The $25 \%$ and $75 \%$ range, as well as the standard deviation and mean $(+)$ are shown $* \mathrm{P}<0.05$.

Table 3. Improvements after BTX/A therapy. Examples for items where patients showed improvement in activities of daily living after BTX/A therapy

\begin{tabular}{lll}
\hline \hline Parameters & Self-Care & Mobility \\
\hline $\begin{array}{l}\text { Functional } \\
\text { skill }\end{array}$ & $\begin{array}{l}\text { Management } \\
\text { with shoes } \\
(\mathrm{n}=3) \\
\text { Toileting tasks } \\
(\mathrm{n}=3)\end{array}$ & $\begin{array}{l}\text { Walking upstairs, } \\
\text { downstairs } \\
(\mathrm{n}=3)\end{array}$ \\
& $\begin{array}{l}\text { Toileting } \\
(\mathrm{n}=2)\end{array}$ & $\begin{array}{l}\text { Chair } / \text { toilet } \\
\text { transfer }(\mathrm{n}=3) \\
\text { Caregiver }\end{array}$ \\
assistance & & $\begin{array}{l}\text { Bed mobility / } \\
\text { transfer }(\mathrm{n}=3)\end{array}$ \\
\hline \hline
\end{tabular}

from chair to toilet without help. His PEDI score in the caregiver assistance of the mobility domain improved from $48.5 \%$ to $52.3 \%$.

\section{Discussion}

In our study, patients with cerebral palsy treated with BTX/A showed a significant functional improvement when evaluated by PEDI. The local effect of BTX/A and the improvement in gross motor function demonstrated in previous studies seem to positively influence activities of daily living.

In order to discuss the results of therapy in this study, evaluation instruments should be classified according to the level of evaluation.
Table 4. Results of evaluation using the GMFM pre- and post-treatment with BTX/A

\begin{tabular}{lll}
\hline \hline & \multicolumn{2}{c}{ Goal Score } \\
& Pre & Post \\
\hline GMFM & 50 & $53 *$ \\
& $46.0 / 23.6 / 81.3$ & $51.1 / 22.8 / 80.1$ \\
& $(7.7-95)$ & $(15-97)$ \\
& & \\
\hline \hline
\end{tabular}

$* \mathrm{P}<0.05$. Indicated are the mean (first line), the median, the $25^{\text {th }}$ and the $75^{\text {th }}$ percentile score (second line) as well as the range (third line).

Such a classification system has been established by the American Academy for Cerebral Palsy and Developmental Medicine (AACPDM), which is commonly quoted in the literature (32). The structure of PEDI corresponds to the classification of AACPDM, where by the domain of functional skills evaluates the level of functional limitations, the domain of caregiver assistance, and the modification scale may be partly classified as an evaluation of disability. Our patients showed changes mainly in the dimension of caregiver assistance. Following therapy, the support of the patients by parents and other caregivers was significantly reduced regarding in particular mobility (transfer) and self-care (toileting). The impact on activities of daily living was demonstrated by the case report. Interestingly, the GMFM goal score did not improve significantly in our study. This may reflect important differences between the GMFM and PEDI as assessment 
instruments. The GMFM measures basic gross motor functions by an independent rater in a standardized environment, while PEDI measures performance in the daily environment as assessed by parents or caregivers. Thus, compared with GMFM, PEDI reflects better the actual environment and measures (at least in part) functioning on the level of disability according to the AACPDM classification. In this context PEDI might be sensitive to changes of motor function that are relatively small, but still significant for activities of daily living. However, PEDI is based on an interview with the parents and is more likely to be influenced by specific expectations and subjective judgements. Therefore, both instruments, PEDI and GMFM provide important information regarding the effectiveness of the therapy in an individual patient and should thus be used as complementary assessment instruments.

Our data indicates that in patients with cerebral palsy, BTX/A therapy of the lower extremity can reduce disability. Because this pilot study was performed as an open design without control group, the strength of our conclusion regarding the evidence on the effectiveness of BTX/A therapy is limited. Nevertheless, the short observation interval after therapy, during which effect on the PEDI was seen, makes it unlikely that our data represent cerebral palsy's natural course. However, a nonspecific effect, not directly related to the BTX/A therapy, cannot be excluded. Our data suggest that the PEDI is a suitable instrument for the evaluation of this kind of medical intervention and it should be used in larger controlled clinical studies.

\section{References}

1. Mall V, Heinen F, Linder M, Philipsen A, Korinthenberg R. Treatment of cerebral palsy with botulinum toxin A: functional benefit and reduction of disability. Three case reports. Pediatr Rehabil 1997; 1: 235-237.

2. Heinen F, Wissel J, Philipsen A, et al. Interventional neuropediatrics: treatment of dystonic and spastic muscular hyperactivity with botulinum toxin A. Neuropediatrics 1997; 28: 307-313.

3. Corry IS, Cosgrove AP, Walsh EG, McClean D. Graham HK. Botulinum toxin A in the hemiplegic upper limb: a double-blind trial. Dev Med Child Neurol 1997; 39: 185-193.

4. Koman LA, Mooney JF 3rd, Smith BP, Goodman A, Mulvaney T. Management of spasticity in cerebral palsy with botulinum-A toxin: report of a preliminary. randomized. double-blind trial. J Pediatr Orthop 1994; 14: 299-303.

5. Koman LA, Mooney JF 3rd, Smith BP, Walker F, Leon JM. Botulinum toxin type A neuromuscular blockade in the treatment of lower extremity spasticity in cerebral palsy: a randomized doubleblind placebo-controlled trial. BOTOX Study Group. J Pediatr Orthop 2000; 20: 108-115.

6. Sutherland DH, Kaufman KR, Wyatt MP, Chambers
HG, Mubarak SJ. Double-blind study of botulinum A toxin injections into the gastrocnemius muscle in patients with cerebral palsy. Gait Posture 1999; 10: 1-9.

7. Yang TF, Chan RC, Chuang TY, Liu TJ, Chiu JW. Treatment of cerebral palsy with botulinum toxin: evaluation with gross motor function measure. J Formos Med Assoc 1999; 98: 832-836.

8. Bohannon RW, Smith MB. Interrater reliability of a modified Ashworth scale of muscle spasticity. Phys Ther 1987; 67: 206-207.

9. Ketelaar M, Vermeer A, Helders PJ. Functional motor abilities of children with cerebral palsy: a systematic literature review of assessment measures. Clin Rehabil 1998; 12: 369-380.

10. Russell DJ, Rosenbaum PL, Cadman DT, Gowland C, Hardy S, Jarvis S. The gross motor function measure: a means to evaluate the effects of physical therapy. Dev Med Child Neurol 1989; 31: 341-352.

11. Haley SM, Coster WJ, Ruth MF. A content validity study of the pediatric evaluation of disability inventory. Pediatr Phys Ther 1991; 3: 177-184.

12. Abel MF, Damiano DL, Pannunzio M, Bush J. Muscle-tendon surgery in diplegic cerebral palsy: functional and mechanical changes. J Pediatr Orthop 1999; 19: 366-375.

13. Almeida GL, Campbell SK, Girolami GL, Penn RD, Corcos DM. Multidimensional assessment of motor function in a child with cerebral palsy following intrathecal administration of baclofen. Phys Ther 1997; 77: 751-764.

14. Bower E, McLellan D, Arney J, Campell MJ. A randomised controlled trial of different intensities of physiotherapy and different goal-setting procedures in 44 children with cerepral palsy. Dev Med Child Neurol 1996; 38: 226-237.

15. Flett PJ, Stern LM, Waddy H, Seeger JD, Gibson SK. Botulinum toxin A versus fixed cast stretching for dynamic calf tightness in cerebral palsy. J Paediatr Child Health 1999; 35: 71-77.

16. Graveline C, Hwang P, Bone G, et al. Evaluation of gross and fine motor functions in children with hemidecortication: predictors of outcomes and timing of surgery. J Child Neurol 1999; 14: 304-315.

17. Heinen F, Linder M, Mall V, et al. Adductor spasticity in children with cerebral palsy and treatment with botulinum toxin type A - the parents' view of functional outcome. Eur J Neurol 1999; 6: 47-50.

18. Hodgkinson I, Berard C, Jindrich ML, Sindou M, Mertens P, Berard J. Selective dorsal rhizotomy in children with cerebral palsy. Results in 18 cases at one year postoperatively. Stereotact Funct Neurosurg 1997; 69: 259-267.

19. Mall V, Heinen F, Kirschner J, et al. Evaluation of botulinum toxin A therapy in children with adductor spasm by gross motor function measure. J Child Neurol 2000; 15: 214-217.

20. McGibbon NH, Andrade CK, Widener G, Cintas HL. Effect of an equine-movement therapy program on gait, energy expenditure, and motor function in children with spastic cerebral palsy: a pilot study. Dev Med Child Neurol 1998; 40: 754-762.

21. McLaughlin JF, Bjornson KF, Astley SJ, et al. Selective dorsal rhizotomy: efficacy and safety 
in an investigator-masked randomized clinical trial. Dev Med Child Neurol 1998; 40: 220-232.

22. Montgomery D, Goldberg J, Amar M, et al. Effects of hyperbaric oxygen therapy on children with spastic diplegic cerebral palsy: a pilot project. Undersea Hyperb Med 1999; 26: 235-242.

23. Riedel $M$, Kraemer $M$, Lohse-Busch $H$, et al. Rehabilitation bei Kindern mit zerebralen Bewegungsstörungen mit den Mitteln der Manuellen Medizin - Erste Ergebnisse des "Gross Motor Function Measure". Phys Rehab Kur Med 1999; 9: 184-186 (in German).

24. Steinbok P, Reiner AM, Beauchamp R, Armstrong RW, Cochrane DD, Kestle J. A randomized clinical trial to compare selective posterior rhizotomy plus physiotherapy with physiotherapy alone in children with spastic diplegic cerebral palsy. Dev Med Child Neurol 1997; 39: 178-184.

25. Steinbok P, Reiner A, Kestle JR. Therapeutic electrical stimulation following selective posterior rhizotomy in children with spastic diplegic cerebral palsy: a randomized clinical trial. Dev Med Child Neurol 1997; 39: 515-520.

26. Wright FV, Sheil EM, Drake JM, Wedge JH, Naumann S. Evaluation of selective dorsal rhizotomy for the reduction of spasticity in cerebral palsy: a randomized controlled trial. Dev Med Child Neurol 1998; 40: 239-247.

27. Nordmark E, Jarnlo GB, Hagglund G. Comparison of the Gross Motor Function Measure and Paediatric Evaluation of Disability Inventory in assessing motor function in children undergoing selective dorsal rhizotomy. Dev Med Child Neurol 2000; 42: 245-252.

28. Bloom KK, Nazar GB. Functional assessment following selective posterior rhizotomy in spastic cerebral palsy. Childs Nerv Syst 1994; 10: 84-86.

29. Dudgeon BJ, Libby AK, McLaughlin JF, Bjornson KF, Roberts TS. Prospective measurement of functional changes after selective dorsal rhizotomy. Arch Phys Med Rehabil 1994; 75: 46-53.

30. Fehlings D, Rang M, Glazier J, Steele J. An evaluation of botulinum-A toxin injections to improve upper extremity function in children with hemiplegic cerebral palsy. J Pediatr 2000; 137: 331337.

31. McCarthy ML, Silberstein CE, Atkins EA, Harryman SE, Sponseller PD, Hadley-Miller NA. Comparing reliability and validity of pediatric instruments for measuring health and well-being of children with spastic cerebral palsy. Dev Med Child Neurol 2002; 44: 468-476.

32. Butler C, Chambers H, Goldstein M, et al. Evaluating research in developmental disabilities: a conceptual framework for reviewing treatment outcomes. Dev Med Child Neurol 1999; 41: 55-59.

33. Palisano R, Rosenbaum P, Walter S, Russell D, Wood E, Galuppi B. Development and reliability of a system to classify gross motor function in children with cerebral palsy. Dev Med Child Neurol 1997; 39: 214-223. 